\author{
Military Technical \\ College \\ Kobry El-Kobba \\ Cairo, Egypt
}

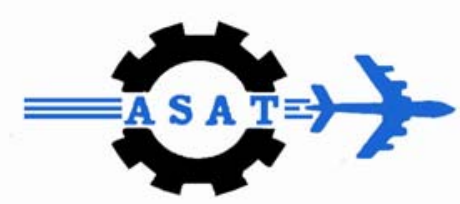

12-th International

Conference on

Aerospace Sciences \&

Aviation Technology

\title{
EXPERIMENTAL MEASUREMENTS OF MISSILE DYNAMIC CHARACTERISTICS
}

\author{
G.A. El-Sheikh* and A-N. Zayed`
}

\begin{abstract}
Determination of a missile dynamic characteristics or parameters and aerodynamic derivatives are indispensable when analyzing the flight path trajectory. The missile dynamic parameters include its center of pressure (c.p.) location, the center of gravity (c.g.) location and the moments of inertia around the principal axes. These parameters can be determined either by the vectorial sum of those for individual sections in the missile or globally by measurement with appropriate laboratory installations. The experimental measurements are considered the more accurate as it considers the interactions or interferences between different parts of the missile body with different sources of anomalies. Therefore, this paper is devoted to describe the procedure of measuring the missile c.g. and moments of inertia experimentally. Then, it is complemented with a numerical case study for its justification.
\end{abstract}

\section{KEYWORDS:}

Guidance and Control, Aerodynamics, Mechanics of Flight

\section{1- THEORETICAL BACKGROUND}

\subsection{Introduction}

Determination of the aerodynamic derivatives is considered as an essential procedure when analyzing the flight path trajectory, where the aerodynamic forces and moments are the main parameters that determine its flight dynamics. As accurately these derivatives are calculated, as accurately the flight path trajectory is determined and consequently the autopilot to be designed. The evaluation or enhancement of the guidance, control, and autopilot behavior necessitates a threedimensional representation of the aerodynamic coefficients for forces and moments. The intent of this representation is to be able to analyze the missile performance throughout its potential operational regimes. The six-degree-of-freedom trajectory simulation, using these three dimensional data, can be used to predict the missile performance against maneuvering targets and to troubleshoot flight problems by reconstructing the flight trajectory from on-board measurements of missile parameters. Aerodynamic forces and moments acting on the missile depend on a set

"Science Valley Academy (SVA), High Institute of Engineering and Technology

`Egyptian Armed Forces 
of aerodynamic coefficients. Wind tunnel tests are considered as the accurate way for estimating these aerodynamic coefficients. However for the theoretical estimation, these coefficients are obtained by the computational fluid dynamics calculations. It is usual to incorporate the aerodynamic descriptions in the equations of motion in the form of aerodynamic stability derivatives. These derivatives are calculated for the body and each of the aerodynamic surfaces, together with estimates for the interference effects of the various components on each other and for different Mach numbers.

This paper is devoted to describe the procedure of measuring the missile c.g. and moments of inertia experimentally and it is complemented with a numerical example for its justification. Since, the position of missile c.g., mass and moments of inertia depend on the fuel consumption and to simplify the computations, the time dependence of these parameters is considered to be linear. That is, the values of these variables can be calculated at any instant if the corresponding values at ignition and at burnout of the missile motor were known. The c.g. measurements include the longitudinal and lateral components while the moment of inertial measurement include the pitch, yaw and roll components along the body axes. By experimentation one can obtain accurate values for the missile c.g. location and its moments of inertia. It is believed that this approach and the algorithmic steps presented in the paper will be quit helpful for both academic colleagues and for the engineers working in practice concerned with that field.

\subsection{Center of Gravity}

The position of the center of gravity may be determined by applying a nonzero moment relative to it and yet have a zero moment applied relative to the origin of the body-fixed coordinate system as depicted by the following equation:

$$
\sum \mathrm{r}_{\mathrm{i}} * \mathrm{~F}_{\mathrm{i}}=0
$$

Where; $F_{i}$ is the $\mathrm{i}^{\text {th }}$ applied force vector, and $r_{i}$ is the position vector from origin of body-fixed coordinate system to the point of $F_{i}$ application. However, to determine the center of gravity position of the missile, the center of gravity position of each section is to be determined. Then, the total center of gravity position of the missile can be determined by:

$$
\mathrm{x}_{\mathrm{cg}}=\frac{\sum_{\mathrm{i}=1}^{\mathrm{n}} \mathrm{x}_{\mathrm{cg}_{\mathrm{i}}} \mathrm{m}_{\mathrm{i}}}{\mathrm{m}}
$$

Where $\mathrm{x}_{\mathrm{cg}_{\mathrm{i}}}$ is the center of gravity of the part number $\mathrm{i}, m_{i}$ is the mass of that part, and $m$ is the total missile mass.

Assuming that the distances, to the center of gravity of each part, are measured from the rear end of the missile as shown in Fig.1 where the nose is taken as a conical shape and all of the wings, fins and canards are taken as right trapezoidal. For simplicity, the wings, fins and canards are assumed of homogeneous distributed mass. 


\subsection{Center of pressure}

The position of the total missile center of pressure $\bar{x}_{\mathrm{cp}}$ is given by the following relation:

$$
\overline{\mathrm{x}}_{\mathrm{cp}}=\frac{\mathrm{x}_{\mathrm{Fa}} \mathrm{C}_{\mathrm{y}_{1}}^{\alpha}+\mathrm{x}_{\mathrm{F}_{\delta}} \mathrm{C}_{\mathrm{y}_{1}}^{\delta}}{\mathrm{C}_{\mathrm{y}_{1}}^{\alpha}+\mathrm{C}_{\mathrm{y}_{1}}^{\delta}}
$$

Where $\mathrm{X}_{\mathrm{Fa}}$ is the neutral point due to angle of attack, $\mathrm{X}_{\mathrm{F} \delta}$ is the neutral point due to the control surface deflection, $C_{y_{1}}^{\alpha}$ is the lift force derivative due to the angle of attack, and $\mathrm{C}_{\mathrm{y}_{1}}^{\delta}$ is the lift force derivative due to the elevator deflection, for more details refer to [1]. When the center of pressure is behind the center of gravity, the missile is called statically stable. In the subsonic range, the Mach number causes the center of pressure to increase and goes back from the missile nose. While, in the supersonic range as the Mach number increases the center of pressure goes forward the missile nose [2].

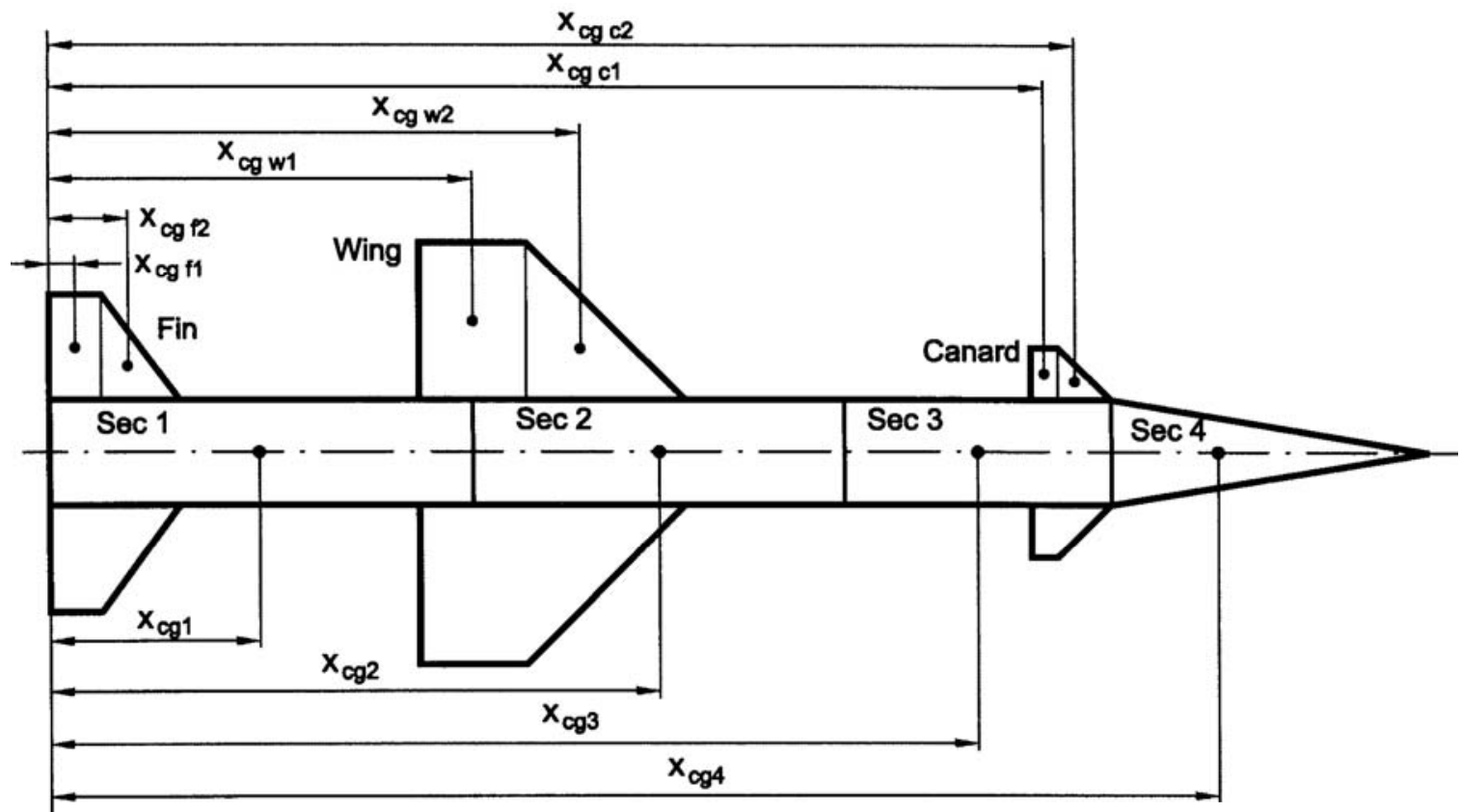

Fig. 1 Locations of the centers of gravity of the main parts of a missile

\subsection{Dynamic point}

The dynamic point of the missile is given by the following relation:

$$
\overline{\mathrm{x}}_{\mathrm{damp}}=\overline{\mathrm{x}}_{\mathrm{cp}}-\frac{\mathrm{m}_{\mathrm{z}_{1}}^{\omega_{\mathrm{z}}}}{\mu}
$$

Where $\bar{x}_{\text {damp }}$ is the relative missile dynamic point with respect to the missile reference length $\ell_{\text {ref }}, \bar{x}_{\text {cp }}$ is the relative missile center of pressure with respect to the missile reference length, $\mathrm{m}_{\mathrm{z}_{1}}^{\omega_{\mathrm{z}}}$ is the pitch moment derivative due to the missile pitching angle rate and $\mu$ is given by:

$$
\mu=\frac{2 \mathrm{~m}}{\rho \mathrm{s}_{\text {ref }} \ell_{\text {ref }}}
$$

If the missile mass is higher than $m_{z_{1}}^{\omega_{z}}$, then the factor $\mu$ is higher than $m_{z_{1}}^{\omega_{z}}$ and consequently the term $\left(\mathrm{m}_{\mathrm{z}_{1}}^{\omega_{\mathrm{z}}} / \mu\right)$ is very small with respect to $\overline{\mathrm{x}}_{\mathrm{cp}}$. This means that the 
missile dynamic point is very close to the center of pressure, and then the damping coefficient of the missile dynamics is small.

\subsection{Moments of inertia}

The moments of inertia of the missile can be determined depending on the definition of the kinetic energy. Where in the case of moment-free-motion, the rotational kinetic energy is conserved and hence the following equation defines an ellipsoid in the body-fixed coordinate system:

$$
\dot{\omega} \mathrm{I}_{\omega}=2 \mathrm{~K}_{\mathrm{E}_{\mathrm{r}}}
$$

where $\omega$ is the angular rate vector in the body-fixed coordinate system, $I_{\omega}$ is the inertia matrix relative to the center of gravity in body-fixed coordinate system, and $\mathrm{K}_{\mathrm{E}_{\mathrm{r}}}$ is the rotational kinetic energy. Then by measuring the angular rate vector in the body-fixed coordinate system, the inertia matrix relative to the center of gravity in body-fixed coordinate system can be determined. However, to determine the moments of inertia of the missile about the axes passing from its center of gravity, the moment of inertia of each section about the axes passing from its center of gravity is determined. Then, the total moments of inertia of the missile are determined. This procedure is carried out at the instants $t_{0}, t_{1}$, and $t_{2}$. A linear varying moment of inertia of the missile with time between these instants is considered as follows:

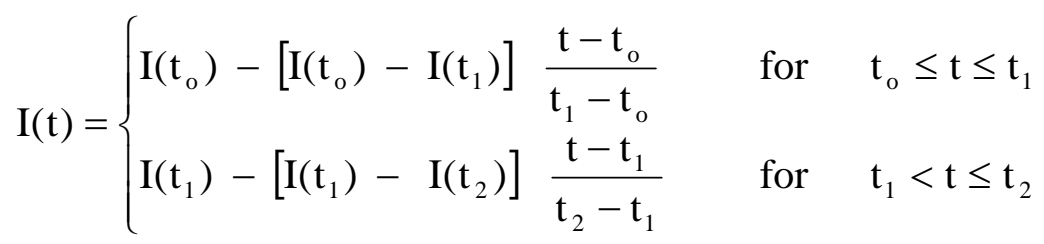

The total moments of inertia of the missile about the axes passing from its center of gravity are determined by the following relations:

$$
\begin{gathered}
I_{X}=\sum_{i=1}^{n} I_{X_{i}} \\
I_{Y}=\sum_{i=1}^{n} I_{Y_{i}} \\
I_{Z}=I_{Y}
\end{gathered}
$$

Where $I_{X}, I_{Y}$, and $I_{Z}$ are the total missile moments of inertia about the axes passing from its center of gravity, while $I_{X_{i}}, I_{Y_{i}}$, and $I_{Z_{i}}$ are the individual parts' moments of inertia about the axes passing from the missile center of gravity. The missile moments of inertia about the $x$ and $y$ axes passing from its center of gravity decrease with time in the boosted and sustained stages; during burning time. After burnout the missile moments of inertia are constant whereas no fuel consumption.

\section{2- DETERMINATION OF MISSILE C.G. LOCATION}

Physical measurements on a hypothetical missile are to be made such that the mass properties of the missile include the total weight, longitudinal and radial center of gravity, and moments of inertia (roll, pitch, and yaw). Two specially designed aluminum rings are placed at structural bulkheads on the missile body. One ring is placed forward and the other ring is placed aft near the missile fin surfaces as shown in Fig. 2. Load cells are attached via cables to the aluminum rings and the entire test 
fixture is attached to an overhead I-beam. The load cells are nulled for weights of the test fixture before the missile is inserted into the aluminum holding rings. With the missile inserted into the test fixture, a set of load cell readings is to be taken at each $90^{\circ}$ rotation of the missile as indicated in Fig. 3 . The geometry of the test fixture and the load cell readings at each missile orientation served as input data for calculating the total weight, radial c.g. location, and longitudinal c.g. location. The missile c.g. is characterized by longitudinal component (related to the missile longitudinal axis) and radial components related to the lateral axes. To clarify this process, a case study is considered in a later section.
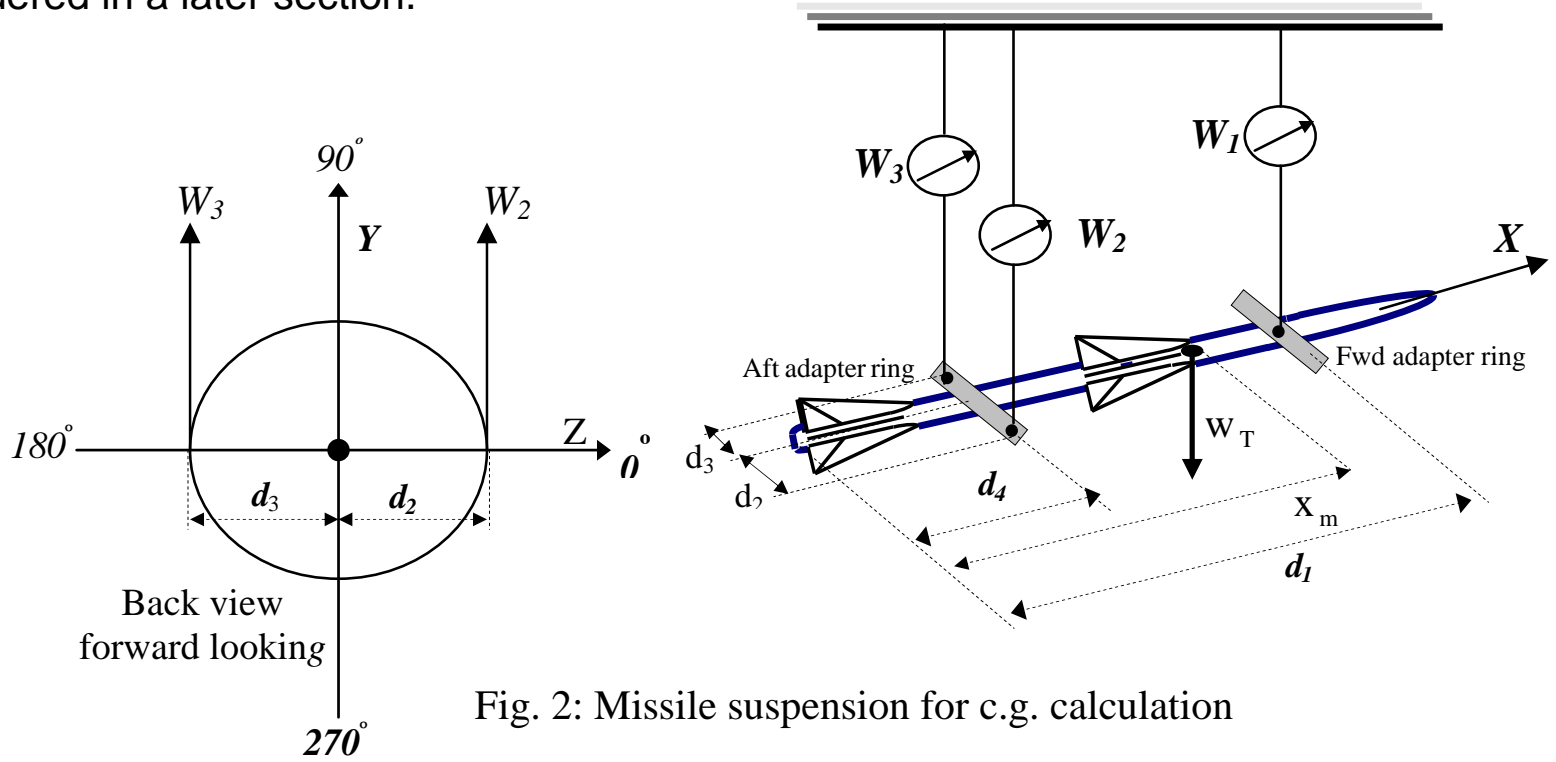

Fig. 2: Missile suspension for c.g. calculation

The objective is to determine the total weight and the position of the center of gravity for the hypothetical missile using the following procedure:

1- The missile is suspended as shown in Fig. 2.

2- The load cells are nulled for weights of the test fixture before insertion of the test item. The following parameters will be recorded: $\left\{\mathrm{w}_{1}, \mathrm{w}_{2}, \mathrm{w}_{3}\right\}$ are weight meters used to represent the respective load cells reading (in $\mathrm{lbs}$ or $\mathrm{kg}$ ), and $\left\{d_{1}, d_{2}, d_{3}, d_{4}\right\}$ are distances from respective load cells to respective test/reference points; Fig. 2. Specifically, $\left\{\mathrm{d}_{1}, \mathrm{~d}_{4}\right\}$ are distances from adapter

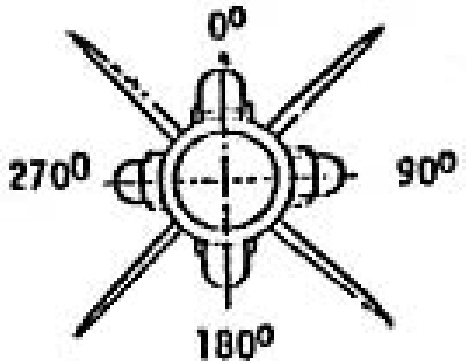

Fig. 3: Back view of the missile rings to the aft end of the missile while $\left\{d_{2}, d_{3}\right\}$ are distances from the back load cells $(2 \& 3)$ to the test longitudinal centerline of the missile.

\subsection{Total weight}

The total weight $\mathrm{w}_{\mathrm{T}}$ of the underlying missile can be obtained as follows:

$$
\mathrm{w}_{\mathrm{T}}=\mathrm{w}_{1_{\mathrm{av}}}+\mathrm{w}_{2_{\mathrm{av}}}+\mathrm{w}_{3_{\mathrm{av}}}
$$

\subsection{Longitudinal c.g.}

The longitudinal c.g. of the underlying missile can be obtained via the balance of moments at a reference point as follows:

The summation of moments about the aft end of the missile is zero i.e. 


$$
\mathrm{w}_{\mathrm{a}_{\mathrm{av}}} \mathrm{d}_{1}+\mathrm{w}_{\mathrm{2}_{\mathrm{av}}} \mathrm{d}_{4}+\mathrm{w}_{3_{\mathrm{av}}} \mathrm{d}_{4}-\mathrm{w}_{\mathrm{T}} \mathrm{x}_{\mathrm{m}}=0
$$

Where $\mathrm{x}_{\mathrm{m}}$ represents the position of the longitudinal c.g. from the aft end and given as

$$
\mathrm{X}_{\mathrm{m}}=\frac{\mathrm{w}_{1_{\mathrm{av}}} \mathrm{d}_{1}+\mathrm{w}_{2_{\mathrm{av}}} \mathrm{d}_{4}+\mathrm{w}_{3_{\mathrm{av}}} \mathrm{d}_{4}}{\mathrm{w}_{\mathrm{T}}}
$$

\subsection{Lateral c.g.}

The radial (lateral displacement of the) c.g. of the underlying missile can be obtained via the balance of respective moments at a reference point as follows:

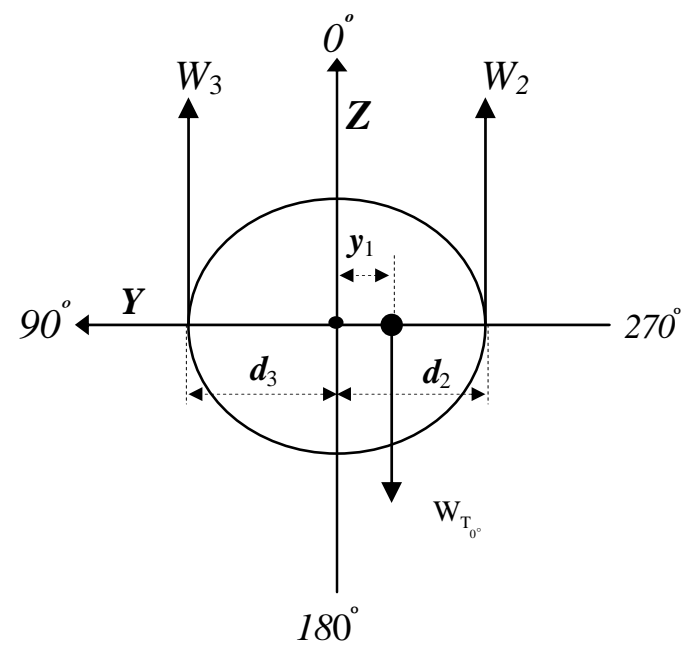

Fig. 4: Suspension with $0^{\circ}$ up

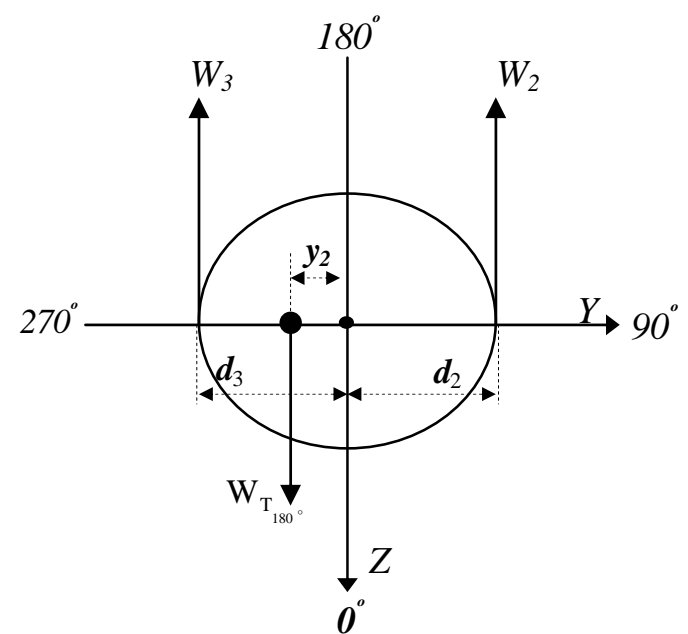

Fig. 5: Suspension with $180^{\circ}$ up

\subsubsection{Y-axis component}

As illustrated in Fig. 4, if $\mathrm{w}_{2}$ is greater than $\mathrm{w}_{3}$, then the lateral displacement of the c.g. is toward the $270^{\circ}$ direction and thus the summation of moments about the centerline of the missile is zero i.e.

$$
\mathrm{w}_{2} \mathrm{~d}_{2}-\mathrm{w}_{3} \mathrm{~d}_{3}-\mathrm{w}_{\mathrm{T}_{0^{\circ}}} \mathrm{y}_{1}=0
$$

Where $\mathrm{y}_{1}$ represents the position of the radial c.g. from the centerline and given as

$$
\mathrm{y}_{1}=\frac{\mathrm{w}_{2} \mathrm{~d}_{2}-\mathrm{w}_{3} \mathrm{~d}_{3}}{\mathrm{w}_{\mathrm{T}_{\mathrm{o}}}}
$$

In reference to Fig. 5 , if $\mathrm{w}_{3}$ is greater than $\mathrm{w}_{2}$, then the lateral displacement of the c.g. is toward the $270^{\circ}$ direction and thus the summation of moments about the centerline of the missile is zero i.e.

$$
\mathrm{w}_{2} \mathrm{~d}_{2}-\mathrm{w}_{3} \mathrm{~d}_{3}+\mathrm{w}_{\mathrm{T}_{180^{\circ}}} \mathrm{y}_{2}=0
$$

Where $\mathrm{y}_{2}$ represents the position of the radial c.g. from the centerline and given as

$$
\mathrm{y}_{2}=\frac{\mathrm{w}_{3} \mathrm{~d}_{3}-\mathrm{w}_{2} \mathrm{~d}_{2}}{\mathrm{w}_{\mathrm{T}_{180^{\circ}}}}
$$

Thus, the coordinate of the missile radial c.g. w.r.t. the y-axis is given by

$$
\overline{\mathrm{y}}_{\mathrm{m}}=\frac{\mathrm{y}_{1}+\mathrm{y}_{2}}{2}
$$


Since $\mathrm{y}_{1}>\mathrm{y}_{2}$, the radial c.g. component along the $\mathrm{y}$-axis is toward $\mathrm{y}_{1}$ or toward $270^{\circ}$ and consequently its reference diagram is given as -ve value.

\subsubsection{Z-axis component}

According to Fig. 6 , if $\mathrm{w}_{3}$ is greater than $\mathrm{w}_{2}$, then the lateral displacement of the c.g. is toward the $180^{\circ}$ direction and thus the summation of moments about the centerline of the missile is zero i.e.

$$
\mathrm{w}_{2} \mathrm{~d}_{2}-\mathrm{w}_{3} \mathrm{~d}_{3}+\mathrm{w}_{\mathrm{T}_{90^{\circ}}} \mathrm{z}_{1}=0
$$

Where $\mathrm{z}_{1}$ represents the position of the radial c.g. from the centerline and given as

$$
\mathrm{z}_{1}=\frac{\mathrm{w}_{3} \mathrm{~d}_{3}-\mathrm{w}_{2} \mathrm{~d}_{2}}{\mathrm{w}_{\mathrm{T}_{90^{\circ}}}}
$$

As shown in Fig. 7, if $\mathrm{w}_{2}$ is greater than $\mathrm{w}_{3}$, then the lateral displacement of the c.g. is toward the $270^{\circ}$ direction and thus the summation of moments about the centerline of the missile is zero i.e.

$$
\mathrm{w}_{2} \mathrm{~d}_{2}-\mathrm{w}_{3} \mathrm{~d}_{3}-\mathrm{w}_{\mathrm{T}_{270^{\circ}}} \mathrm{z}_{2}=0
$$

Where $z_{2}$ represents the position of the radial c.g. from the centerline and given as

$$
\mathrm{z}_{2}=\frac{\mathrm{w}_{2} \mathrm{~d}_{2}-\mathrm{w}_{3} \mathrm{~d}_{3}}{\mathrm{w}_{\mathrm{T}_{270^{\circ}}}}
$$

Now, the coordinate of the missile radial c.g. w.r.t. the $z$-axis is given by

$$
\overline{\mathrm{z}}_{\mathrm{m}}=\frac{\mathrm{z}_{1}+\mathrm{z}_{2}}{2}
$$

Since $\mathrm{z}_{2}>\mathrm{z}_{1}$, the radial c.g. component along the $\mathrm{z}$-axis is toward $\mathrm{z}_{2}$ or toward $180^{\circ}$ and consequently its reference diagram is given as -ve value.

Finally, the c.g. of the underlying missile w.r.t. its aft end and body axes is initially at the following coordinates:

$$
\overline{\mathrm{x}}_{\mathrm{cg}}=\left[\begin{array}{lll}
\overline{\mathrm{x}}_{\mathrm{m}} & \overline{\mathrm{y}}_{\mathrm{m}} & \overline{\mathrm{z}}_{\mathrm{m}}
\end{array}\right]
$$

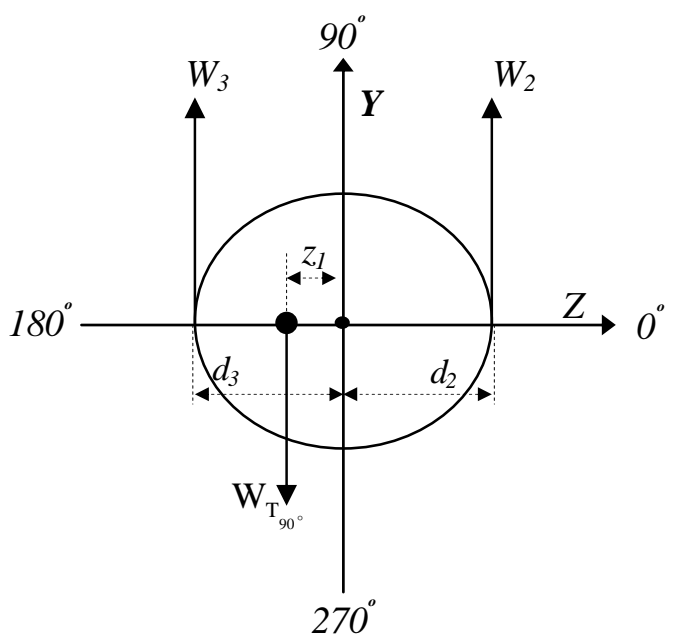

Fig. 6: Suspension with $90^{\circ}$ up

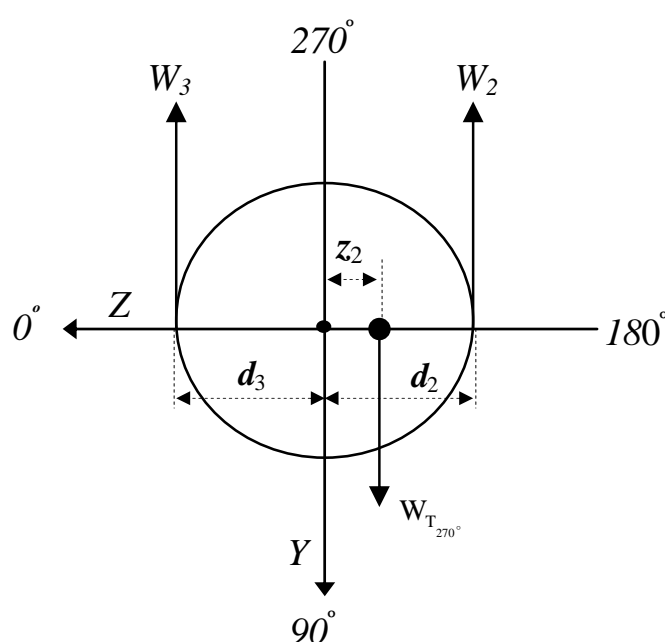

Fig. 7: Suspension with $270^{\circ}$ up 


\section{3- DETERMINATION OF MISSILE MOMENTS OF INERTIA}

\subsection{Pitch and yaw moments of inertia}

The pitch and yaw moments of inertia are measured using the bifilar (two supporting cables) pendulum method with the cables 100 inches apart. The moment of inertia of the supporting I-beam and related hardware is subtracted out of the measured moments of inertia for the final result. The pitch moment is measured with $0^{\circ}$ reference up. The yaw moment is found simply by repeating the experiment with the missile rotated $90^{\circ}$. Recorded test data and detailed calculations for the pitch and yaw moments are given in a case study later.

\subsection{Roll moment of inertia}

\subsubsection{Quadfilar pendulum method}

The missile roll moment is calculated from roll moment measurements of component parts. It is necessary to disassemble the missile to obtain the roll moment for two reasons: the missile boat-tail would not structurally hold the entire missile weight and the complete missile is too long for the facility. The missile is disassembled and separate roll moments are measured for each of the following: booster section, warhead, warhead cover, seeker, and ogive cover. The roll moment of inertia for each component is measured using the quadfilar (4-cable) pendulum method. The four cables are fastened to an overhead structure and the test item is placed on a square plate held by the four cables, one at each corner. The individual roll moments are added directly to yield the complete missile roll moment.

\subsubsection{Rails method}

The measurement of the roll moment of inertia is carried out using inclined rails, Fig. 8 , and depends on the rocket design and configuration. If the rocket is a single piece, that measurement will be carried out for the rocket as a whole. While for rockets compound of multi-sections, the measurement will be carried out for each section, individually, and the rocket roll moment of inertia is then calculated as the sum of the roll inertia moments of all sections.

\subsubsection{Single piece rocket}

The following steps present the processes of measuring the roll moment of inertia:

a) Install two inclined rails having inclination angle " $\alpha$ " with the horizontal as illustrated in Fig. 8.

b) Get a cylinder of length "L" equal the same length of the rocket, mass " $m$ " equals the same mass of the rocket, and radius " $\mathrm{R}_{1}$ " very close to the rocket radius " $\mathrm{R}_{2}$ ".

c) Put two stoppers at positions "A" and "B" separated with a distance

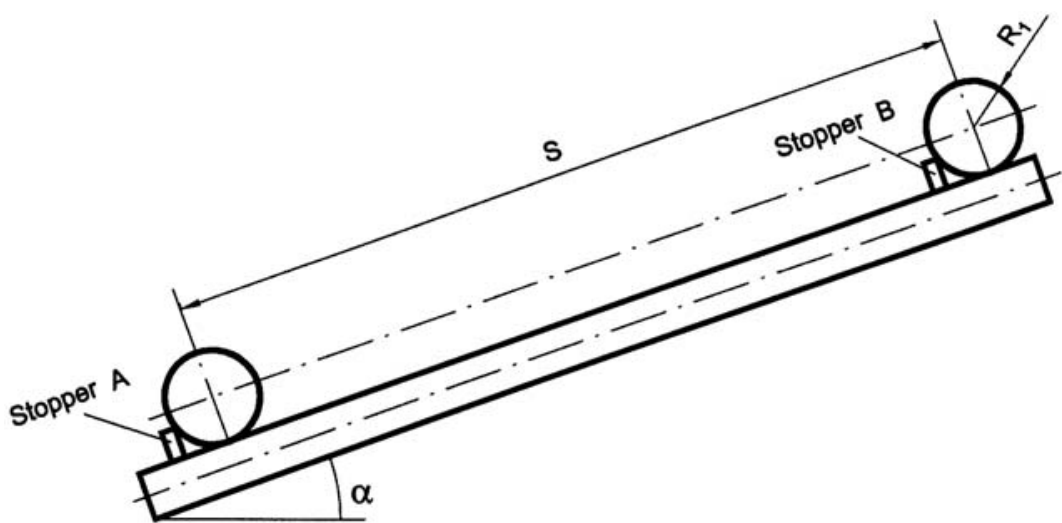

Fig. 8 Installation of the rolling method "S" where $S$ is chosen as multiple of the cylinder circumference $\left(S \approx 2 n \pi R_{1}\right)$.

d) Locate the cylinder behind stopper B. 
e) Remove stopper B to let the cylinder to roll down in the $\mathrm{x}$-direction until it stopped at stopper A. Measure the time of motion (rolling), from stopper B to stopper A, and record that time as " $t_{1}$ ". Note that the rolling should be with no sliding.

f) Repeat steps (d) and (e) for the rocket as a whole and measure and record the rolling time as " $\mathrm{t}_{2}$ ".

g) The roll moment of inertia of the rocket may be calculated as follows [18]:

$$
\mathrm{I}_{\mathrm{r}}=\frac{1}{2} \mathrm{mR}_{2}^{2} \times \frac{\mathrm{t}_{2}^{2}}{\mathrm{t}_{1}^{2}}
$$

\subsubsection{Multi-section rocket}

The missile roll moment is calculated from roll moment measurements of each individual section. The missile is disassembled and separate roll moments are measured for each of the following: booster section, warhead, warhead cover, seeker, and ogive cover. The roll moment of inertia for each section is measured using the method mentioned in the previous section 3.2.2.1. The individual roll moments are added directly to yield the complete missile roll moment. Test data and calculations for roll moments are carried out in an assignment later.

\subsection{Missile inertia moments}

The missile moments of inertia are characterized by a longitudinal component (related to the missile longitudinal axis) and lateral components related to the lateral axes. These moments of inertia can be determined for the underlying missile using the following procedure:

1- The missile is suspended as shown in the Fig. 9, such that the mass center (or c.g.) be at the middle between the two strings

2- Give the missile body an initial angular displacement in the horizontal plane

3- Release the body and

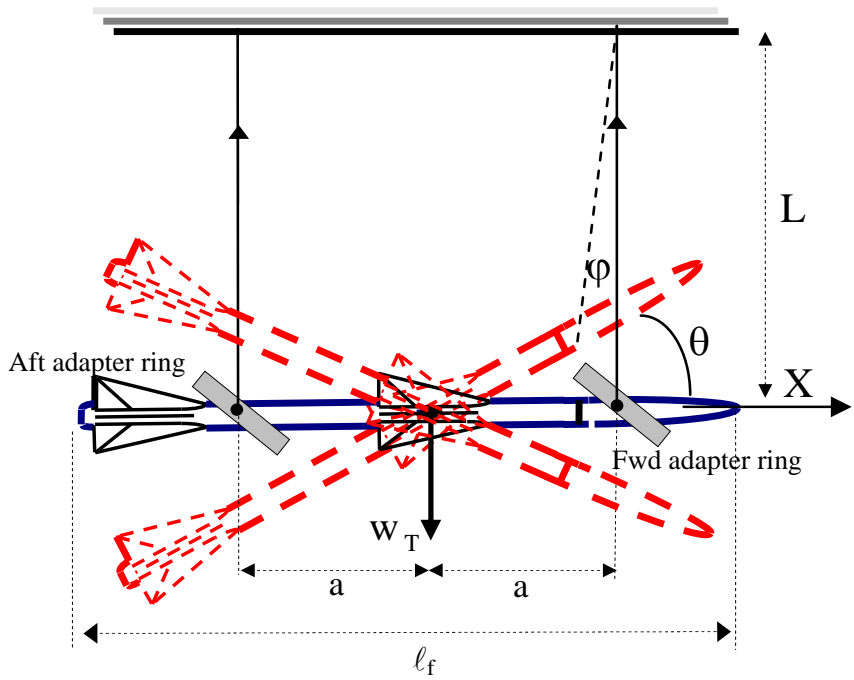

Fig. 9: Missile suspension for moments of inertia calculation leave it to oscillate about its c.g. and measure the time of free oscillations using a stopwatch.

4- Repeat the above process (steps-2, 3) many times and record the number of free oscillations in each case and the time elapsed for it.

5- Then, find the average period $\tau_{\mathrm{av}}$ of oscillation via dividing the total time by the total number of oscillations.

6- Using the average period of oscillation $\tau_{\mathrm{av}}$ and the given data calculate the moment of inertia according to relationships $(23,24,25)$. 


$$
I= \begin{cases}\frac{W_{T} a^{2} \tau_{a v}^{2} k}{16 \pi^{2} L(12)}-I_{m} & \text { for pitch and yaw planes } \\ \frac{W_{T} a^{2} \tau_{a v}^{2} k}{4 \pi^{2} L(12)}-I_{m} & \text { for roll; booster, warhead, seeker, seeker cover } \\ \frac{\text { mass } \frac{\left(d_{o}^{2}+d_{i}^{2}\right)}{4}}{2} & \text { for roll; warhead cover }\end{cases}
$$

Keeping in mind that the difference between characteristics of different missile parts and the inertia moment (pitch/yaw/roll) is to be calculated. The variables utilized in these equations are $k$ is the fixture correction factor, $L$ is the element length, $I_{m}$ is the inertia of mounting plate and the adaptation equipment, while $\mathrm{d}_{\mathrm{o}}$ and $\mathrm{d}_{\mathrm{i}}$ are, respectively, the outer and inner diameters of the warhead cover. The average period $\tau_{\mathrm{av}}$ of free oscillations for the underlying missile can be obtained as follows

$$
\tau_{\mathrm{av}}=\frac{\text { total time of periods }}{\text { total number of periods }}
$$

The pitch $\left(\mathrm{I}_{\mathrm{y}}\right)$ and yaw $\left(\mathrm{I}_{\mathrm{z}}\right)$ moments of inertia for the underlying missile can be obtained using the relationship (23). While, the roll moments of inertia for different parts are obtained using $\mathrm{Eq}^{\underline{\underline{n}}}$ (24) to yield the booster with umbilical $\left(\mathrm{I}_{\mathrm{x}, \mathrm{b}}\right)$, the warhead $\left(I_{x, w}\right)$, the seeker $\left(I_{x, s}\right)$, the seeker ogive cover $\left(I_{x, s c}\right)$, while the warhead cover moment of inertia $\left(\mathrm{I}_{\mathrm{x}, \mathrm{wc}}\right)$ is obtained using $\mathrm{Eq}^{\mathrm{n}}$ (25).

Now, the total roll inertia moment of the underlying missile is the sum of inertia moments for all components as follows:

$$
I_{x}=I_{x, b}+I_{x, w}+I_{x, w c}+I_{x, s}+I_{x, s c}
$$

Finally, the moment of inertia of the underlying missile w.r.t. its body axes has the values $\left[\begin{array}{lll}I_{x} & I_{y} & I_{z}\end{array}\right]$.

\section{4- CASE STUDY}

The underlying missile is aerodynamically controlled via tail control fins and has two planes of symmetry.

\subsection{Missile c.g.}

Considering the previous equations $(9,11,13,15,16,18,20)$ and the following data;

- The recorded distances $\left\{\mathrm{d}_{1}, \mathrm{~d}_{2}, \mathrm{~d}_{3}, \mathrm{~d}_{4}\right\}$ are respectively $384.5[\mathrm{~cm}], 29.8[\mathrm{~cm}]$, $29.8[\mathrm{~cm}]$, and $118.4[\mathrm{~cm}]$

- The recorded readings of the load cells at different angular positions of the missile w.r.t. its longitudinal axis are listed in Table-1.

Then, the total weight $\mathrm{w}_{\mathrm{T}}$ of the underlying missile can be obtained as follows

$$
\mathrm{w}_{\mathrm{T}}=\mathrm{w}_{1_{\mathrm{av}}}+\mathrm{w}_{2_{\mathrm{av}}}+\mathrm{w}_{3_{\mathrm{av}}}=604[\mathrm{~kg}]
$$


Table-1: The load cells readings at different missile positions

\begin{tabular}{|l|l||l||l|}
\hline \multicolumn{1}{|c||}{ Orientation } & \multicolumn{1}{c|}{$\mathrm{w}_{1}[\mathrm{~kg}]$} & $\mathrm{w}_{2}[\mathrm{~kg}]$ & $\mathrm{w}_{3}[\mathrm{~kg}]$ \\
\hline \hline $0^{\circ}$ & 267 & 173 & 164 \\
\hline $90^{\circ}$ & 267 & 167 & 170 \\
\hline $180^{\circ}$ & 267 & 167 & 170 \\
\hline $270^{\circ}$ & 267 & 176.5 & 160 \\
\hline \hline Average & 267 & 171 & 166 \\
\hline
\end{tabular}

\subsubsection{Longitudinal c.g.}

The longitudinal c.g. of the underlying missile can be obtained via the balance of moments at a reference point i.e. the summation of moments about the aft end of the missile is zero. Then, the position of the longitudinal c.g. $x_{m}$ from the aft end is given as

$$
\overline{\mathrm{x}}_{\mathrm{m}}=\frac{\mathrm{w}_{\mathrm{1}_{\mathrm{av}}} \mathrm{d}_{1}+\mathrm{w}_{2_{\mathrm{av}}} \mathrm{d}_{4}+\mathrm{w}_{3_{\mathrm{av}}} \mathrm{d}_{4}}{\mathrm{w}_{\mathrm{T}}}=236[\mathrm{~cm}]
$$

\subsubsection{Lateral c.g.}

\section{- Y-Component}

The radial (lateral displacement of the) c.g. of the underlying missile can be obtained via the balance of respective moments at a reference point. The given data show that $\mathrm{w}_{2}(173 \mathrm{~kg})$ is greater than $\mathrm{w}_{3}(164 \mathrm{~kg})$ and consequently the lateral displacement of the c.g. is toward the $270^{\circ}$ direction. Thus, the summation of moments about the centerline of the missile is zero and the displacement $\mathrm{y}_{1}$ represents the position of the radial c.g. from the centerline and given as

$$
\mathrm{y}_{1}=\frac{\mathrm{w}_{2} \mathrm{~d}_{2}-\mathrm{w}_{3} \mathrm{~d}_{3}}{\mathrm{w}_{\mathrm{T}_{\mathrm{o}}}}=0.444[\mathrm{~cm}]
$$

It is clear from the given data and Fig. 5 that $\mathrm{w}_{3}(170 \mathrm{~kg})$ is greater than $\mathrm{w}_{2}(167$ $\mathrm{kg}$ ) and consequently the lateral displacement of the c.g. is toward the $270^{\circ}$ direction. Thus, the summation of moments about the centerline of the missile is zero and $\mathrm{y}_{2}$ represents the position of the radial c.g. from the centerline and given as

$$
\mathrm{y}_{2}=\frac{\mathrm{w}_{3} \mathrm{~d}_{3}-\mathrm{w}_{2} \mathrm{~d}_{2}}{\mathrm{w}_{\mathrm{T}_{180^{\circ}}}}=0.148[\mathrm{~cm}]
$$

Thus, the coordinate of the missile radial c.g. w.r.t. the y-axis is given by

$$
\overline{\mathrm{y}}_{\mathrm{m}}=\frac{\mathrm{y}_{1}+\mathrm{y}_{2}}{2}=0.296[\mathrm{~cm}]
$$

Since $\mathrm{y}_{1}>\mathrm{y}_{2}$, the radial c.g. component along the $\mathrm{y}$-axis is toward $\mathrm{y}_{1}$ or toward $270^{\circ}$ and consequently its reference diagram is given as

$$
\overline{\mathrm{y}}_{\mathrm{m}}=-0.296[\mathrm{~cm}]
$$




\section{- Z-Component}

The given data and Fig. 6 clarify that $\mathrm{w}_{3}(170 \mathrm{~kg})$ is greater than $\mathrm{w}_{2}(167 \mathrm{~kg})$ and consequently the lateral displacement of the c.g. is toward the $180^{\circ}$ direction. Thus, the summation of moments about the centerline of the missile is zero and $\mathrm{z}_{1}$ represents the position of the radial c.g. from the centerline and given as

$$
\mathrm{z}_{1}=\frac{\mathrm{w}_{3} \mathrm{~d}_{3}-\mathrm{w}_{2} \mathrm{~d}_{2}}{\mathrm{w}_{\mathrm{T}_{90^{\circ}}}}=0.148[\mathrm{~cm}]
$$

The given data and Fig. 7 show that $\mathrm{w}_{2}(176.5 \mathrm{~kg})$ is greater than $\mathrm{w}_{3}(160 \mathrm{~kg})$ and consequently the lateral displacement of the c.g. is toward the $270^{\circ}$ direction. Thus, the summation of moments about the centerline of the missile is zero and $\mathrm{z}_{2}$ represents the position of the radial c.g. from the centerline and given as

$$
\mathrm{z}_{2}=\frac{\mathrm{w}_{2} \mathrm{~d}_{2}-\mathrm{w}_{3} \mathrm{~d}_{3}}{\mathrm{w}_{\mathrm{T}_{270^{\circ}}}}=0.815[\mathrm{~cm}]
$$

Now, the z-coordinate of the missile radial c.g. is given by

$$
\overline{\mathrm{z}}_{\mathrm{m}}=\frac{\mathrm{z}_{1}+\mathrm{z}_{2}}{2}=0.482[\mathrm{~cm}]
$$

Since $z_{2}>z_{1}$, the radial c.g. component along the $z$-axis is toward $z_{2}$ or toward $180^{\circ}$ and consequently its reference diagram is given as $\bar{z}_{\mathrm{m}}=-0.482[\mathrm{~cm}]$.

Finally, the c.g. of the underlying missile w.r.t. its aft end and body axes is initially at the following coordinates:

$$
\left[\begin{array}{lll}
\overline{\mathrm{x}}_{\mathrm{m}} & \overline{\mathrm{y}}_{\mathrm{m}} & \overline{\mathrm{z}}_{\mathrm{m}}
\end{array}\right]=\left[\begin{array}{lll}
236 & -0.296 & -0.482
\end{array}\right][\mathrm{cm}]
$$

\subsection{Missile moment of inertia}

Considering the equations of section-3 and the following data,

- The fixture correction factor is given by

$$
k= \begin{cases}0.996 & \text { for pitch and yaw planes } \\ 0.98475 & \text { for roll; booster } \\ 0.97 & \text { for roll; warhead, seeker and seeker cover }\end{cases}
$$

- The total weight $\mathrm{w}_{\mathrm{T}}$ of the missile/element and mounting equipment a average missile or element weight + beam weight + two cable adapters + forward adapter + aft adapter + aft ring + fwd ring $\}$ is

$$
\mathrm{W}_{\mathrm{T}}= \begin{cases}640[\mathrm{~kg}] & \text { for pitch and yaw planes (missile + adaption) } \\ 579[\mathrm{~kg}] & \text { for roll; (booster + adaption) } \\ 87[\mathrm{~kg}] & \text { for roll; (warhead + adaption) } \\ 63.8[\mathrm{~kg}] & \text { for roll; (seeker + adaption) } \\ 47.7[\mathrm{~kg}] & \text { for roll; (seeker cover + adaption) }\end{cases}
$$

- The inertia of mounting plate and the adaptation equipment \{beam + two cable adapters + fwd adapter + aft adapter + aft ring + fwd ring $\}$ is given by 
- The cable length

$$
I_{m}= \begin{cases}77.6\left[\mathrm{~kg}-\mathrm{m}^{2}\right] & \text { for pitch and yaw planes } \\ 9.7\left[\mathrm{~kg}-\mathrm{m}^{2}\right] & \text { for roll; booster } \\ 3.05\left[\mathrm{~kg}-\mathrm{m}^{2}\right] & \text { for roll; warhead, seeker and seeker cover }\end{cases}
$$

$$
\mathrm{L}= \begin{cases}7.14[\mathrm{~m}] & \text { for pitch and yaw planes } \\ 7.93[\mathrm{~m}] & \text { for roll; booster } \\ 4.79[\mathrm{~m}] & \text { for roll; warhead, seeker and seeker cover }\end{cases}
$$

- The distance from the mass center (of the missile/element under test) to the supporting cable is given as

$$
\mathrm{a}= \begin{cases}254[\mathrm{~cm}] & \text { for pitch and yaw planes } \\ 61[\mathrm{~cm}] & \text { for roll; booster } \\ 49[\mathrm{~cm}] & \text { for roll; warhead, seeker and seeker cover }\end{cases}
$$

\begin{tabular}{|c|c|c|c|c|}
\hline & \multicolumn{2}{|c|}{ Pitch moment of inertia } & \multicolumn{2}{|c|}{ Yaw moment of inertia } \\
\hline Trial & No of Periods & Trial time & No of Periods & Trial time \\
\hline 1 & 25 & 139 & 25 & 139.1 \\
\hline 2 & 25 & 139.1 & 25 & 139 \\
\hline 3 & 25 & 139 & 25 & 139.1 \\
\hline 4 & 25 & 138.8 & 25 & 139 \\
\hline Total & 100 & 555.9 [sec] & 100 & 556.2 [sec] \\
\hline$\tau_{\mathrm{av}}$ & \multicolumn{2}{|c|}{$5.559[\mathrm{sec}]$} & \multicolumn{2}{|c|}{$5.562[\mathrm{sec}]$} \\
\hline I & \multicolumn{2}{|c|}{$\mathrm{I}_{\mathrm{y}}=1028.96\left[\mathrm{~kg}-\mathrm{m}^{2}\right]$} & \multicolumn{2}{|c|}{$\mathrm{I}_{\mathrm{z}}=1030.16\left[\mathrm{~kg}-\mathrm{m}^{2}\right]$} \\
\hline
\end{tabular}

- The recorded data of free oscillations for four trials are listed with the obtained dynamics in the following tables:

\begin{tabular}{|c|c|c|c|c|c|c|}
\hline & \multicolumn{2}{|c|}{ Booster with umbilical } & \multicolumn{2}{|c|}{ Warhead } & \multicolumn{2}{|c|}{ Seeker } \\
\hline Trial & No of Periods & Trial time & No of Periods & Trial time & No of Periods & Trial time \\
\hline 1 & 10 & 18.1 & 25 & 45.4 & 25 & 52.1 \\
\hline 2 & 10 & 18.1 & 25 & 45.4 & 25 & 52.1 \\
\hline 3 & 10 & 18.1 & 25 & 45.4 & 25 & 52.2 \\
\hline 4 & 10 & 18.1 & 25 & 45.3 & 25 & 52.1 \\
\hline \multirow[t]{3}{*}{ Total } & 40 & $72.4[\mathrm{sec}]$ & 100 & $181.5[\mathrm{sec}]$ & 100 & $208.5[\mathrm{sec}]$ \\
\hline & \multicolumn{2}{|c|}{$\tau_{\mathrm{av}}=1.815[\mathrm{sec}]$} & \multicolumn{2}{|c|}{$\tau_{\mathrm{av}}=1.815[\mathrm{sec}]$} & \multicolumn{2}{|c|}{$\tau_{\mathrm{av}}=2.085[\mathrm{sec}]$} \\
\hline & \multicolumn{2}{|c|}{$\mathrm{I}_{\mathrm{x}, \mathrm{b}}=12.16\left[\mathrm{~kg}-\mathrm{m}^{2}\right]$} & \multicolumn{2}{|c|}{$\mathrm{I}_{\mathrm{x}, \mathrm{w}}=0.46\left[\mathrm{~kg}-\mathrm{m}^{2}\right]$} & \multicolumn{2}{|c|}{$\mathrm{I}_{\mathrm{x}, \mathrm{s}}=0.37\left[\mathrm{~kg}-\mathrm{m}^{2}\right]$} \\
\hline
\end{tabular}

\section{Roll moment of inertia}




\begin{tabular}{|c|c|c|c|}
\hline & \multicolumn{2}{|c|}{ Seeker ogive cover } & Warhead cover \\
\hline Trial & No of Periods & Trial time & \multirow{7}{*}{$\begin{array}{l}\text { The warhead cover has a } \\
\text { mass }=2.4[\mathrm{~kg}] \text {, outer } \\
\text { diameter } \mathrm{d}_{\mathrm{o}}=0.33[\mathrm{~m}] \text { and } \\
\text { inner diameter } \mathrm{d}_{\mathrm{i}}=0.326 \\
{[\mathrm{~m}] .}\end{array}$} \\
\hline 1 & 25 & 59.7 & \\
\hline 2 & 25 & 59.5 & \\
\hline 3 & 25 & 59.65 & \\
\hline 4 & 25 & 59.6 & \\
\hline \multirow[t]{3}{*}{ Total } & 100 & $\begin{array}{l}238.45 \\
\text { [sec] }\end{array}$ & \\
\hline & \multicolumn{2}{|c|}{$\tau_{\mathrm{av}}=2.3845[\mathrm{sec}]$} & \\
\hline & \multicolumn{2}{|c|}{$\mathrm{I}_{\mathrm{x}, \mathrm{sc}}=0.26\left[\mathrm{~kg}-\mathrm{m}^{2}\right]$} & $\mathrm{I}_{\mathrm{x}, \mathrm{wc}}=0.0646\left[\mathrm{~kg}-\mathrm{m}^{2}\right]$ \\
\hline
\end{tabular}

Thus, the total roll inertia moment of the missile is the sum of inertia moments for all components as follows:

$$
\begin{aligned}
I_{x} & =I_{x, b}+I_{x, w}+I_{x, w c}+I_{x, s}+I_{x, s c} \\
& =12.16+0.46+0.0646+0.37+0.26 \\
& =13.3146\left[\mathrm{~kg}-\mathrm{m}^{2}\right]
\end{aligned}
$$

Finally, the moment of inertia of the underlying missile w.r.t. its body axes has the following values:

$$
\left[\begin{array}{lll}
I_{x} & I_{y} & I_{z}
\end{array}\right]=\left[\begin{array}{lll}
13.3146 & 1028.96 & 1030.16
\end{array}\right]\left[\mathrm{kg}-\mathrm{m}^{2}\right]
$$

\section{CONCLUSIONS}

This paper described the procedure of measuring the missile c.g. and moments of inertia experimentally and then, it is complemented with a numerical case study for its justification. The c.g. measurements include the longitudinal and lateral components while the moment of inertia measurement include the pitch, yaw and roll components along the body axes. By experimentation one can obtain accurate values for the missile c.g. location and its moments of inertia. It is believed that this approach and the algorithmic steps presented in the paper will be quit helpful for both academic colleagues and for the engineers working in practice concerned with that field.

\section{REFERENCES}

[1] Cimbala, J.M., Mechanical Engineering Measurements, ME-82 course web pages at http://www.me.psu.edu/me82/

[2] Chernobrobkin, L., Dynamic Flight of Non Pilot Vehicle, Moscow, 1973.

[3] Cook, M.V., Flight Dynamics Principles, AIAA, 1996.

[4] Edelson, B., and Allen E.F., Thrust and Drag: Its Prediction and Verification, National Aeronautics and Space Administration, 1985.

[5] Emil, J. (Ed.), Test and Evaluation of The Tactical Missile, AIAA, 1989.

[6] "Eric Weisstein's World of Physics: Torsional Pendulum" from http://scienceworld.wolfram.com/physics/TorsionalPendulum.html Courtesy of Wolfram Research Inc. 
[7] "Eric Weisstein's World of Physics: Moment of Inertia" from http://scienceworld.wolfram.com/physics/MomentOfInertia.html Courtesy of Wolfram Research Inc.

[8] Hemsch, M. J. (Ed.), Tactical Missile Aerodynamics: General Topics, AIAA, vol. 141, 1992.

[9] John, J.B., Aerodynamics for Engineers, AIAA, 1989.

[10] Krasnov, N.F., Methods of Aerodynamic Calculations, Mir Publishers, Moscow, 1985.

[11] Mendenhall, M.R. (Ed.), Tactical Missile Aerodynamics: Prediction Methodology, AIAA, vol. 142, 1996

[12] Meriam J.L. and L.G. Kraige, Engineering Mechanics: Dynamics, Fourth Edition, John Wiley and Sons, 1997.

[13] Morelli, A. E., and Klein V., Accuracy of Aerodynamic Model Parameters Estimated from Flight Test Data, Journal of Guidance, Control, and Dynamics, vol.20, No. 1, 1997, pp. 74-80.

[14] Pitts, W.C., and J.N. Kaatarari, Lift and Center of Pressure of Wing-Body-Tail Combination at Subsonic, Transonic, and Supersonic Speeds, NASA Report 1307.

[15] Steven, J.Z., Soviet Air Defense Missiles, U.K., 1989.

[16] Watanabe, S., and Ishimoto S., Aerodynamic Characteristics Evaluation of Hypersonic Flight Experiment Vehicle Based On Flight Data, Journal of Spacecraft and Rockets, vol. 34, No. 4, 1997, pp. 464-470.

[17] Web Cutter Mechanism image scanned by Professor H. J. Sommer from Edward Haug. Computer Aided Kinematics and Dynamics of Mechanical Systems, Volume 1. Allyn and Bacon. 1989.

[18] Zayed, A-N., Rocket Testing, Military Technical College, PL 1914, October 2002. 